\title{
Avaliação da energia eólica no Brasil utilizando a análise SWOT e PESTEL
}

\author{
Evaluation of wind energy in Brazil using SWOT and PESTEL analysis
}

\section{Évaluation de l'énergie éolienne au Brésil en utilisant l'analyse SWOT et PESTEL}

Evaluación de la energía eólica en el Brasil utilizando el análisis SWOT y PESTEL

\author{
Vitor Silva Damasceno ${ }^{1}$ \\ Yolanda Vieira de $\mathrm{Abreu}^{1}$
}

Recebido em 05/07/2017; revisado e aprovado em 01/10/2017; aceito em 17/10/2017

DOI: http://dx.doi.org/10.20435/inter.v19i3.1649

\begin{abstract}
Resumo: O presente estudo tem o objetivo de analisar a geração da energia eólica no Brasil. Para tanto, foi utilizado o método de SWOT para verificar a situação atual da fonte eólica, contando com a análise PESTEL, aplicando a escala Likert. A fonte apresenta-se como interessante e importante energia para o Brasil, com características naturais favoráveis para realização do investimento.
\end{abstract}

Palavras-chave: energia eólica; PESTEL; SWOT.

Abstract: The present study has as objective to analyze the generation of wind energy in Brazil. Therefore, the SWOT method was used to verify the current situation of the wind energy source, including on the PESTEL analysis, applying the Likert scale. The source presents as an interesting and important energy for Brazil, having favorable natural characteristics to realize the investment.

Keywords: wind energy; PESTEL; SWOT.

Résumé: La présente étude vise à analyser la production d'énergie éolienne au Brésil. A cet effet, la méthode SWOT a été utilisée pour vérifier la situation actuelle de la source d'énergie éolienne, en se basant sur l'analyse PESTEL, en appliquant l'échelle Likert. La source se présente comme une énergie intéressante et importante pour le Brésil, avec des caractéristiques naturelles favorables à la réalisation de l'investissement.

Mots-clés: énergie éolienne; PESTEL; SWOT.

Resumen: El presente estudio tiene el objetivo de analizar la generación de la energía eólica en Brasil. Para ello, se utilizó el método de SWOT para verificar la situación actual de la fuente eólica, incluso el análisis PESTEL, aplicando la escala Likert. La fuente se presenta como interesante e importante energía para Brasil, con características naturales favorables para la realización de la inversión.

Palabras clave: energía eólica; PESTEL; SWOT.

\section{INTRODUÇÃO}

A energia eólica é uma fonte considerada limpa e está em expansão em grande parte do mundo. O Global Status Report (GSR, 2016) classifica a energia eólica como uma fonte de energia em pleno crescimento e com capacidade para atender a demanda futura de eletricidade.

No Brasil, o Balanço Energético Nacional (BEN) (BRASIL, 2016) apresentou aumento significativo na geração eólica, o qual, em 2007, era de 663 GWh e passou a 21.625 GWh em 2015, aumento de cerca de 32 vezes, conforme demonstrado na Figura 1.

\footnotetext{
${ }^{1}$ Universidade Federal do Tocantins (UFT), Palmas, Tocantins, Brasil.
} 
Figura 1 - Evolução da geração eólica

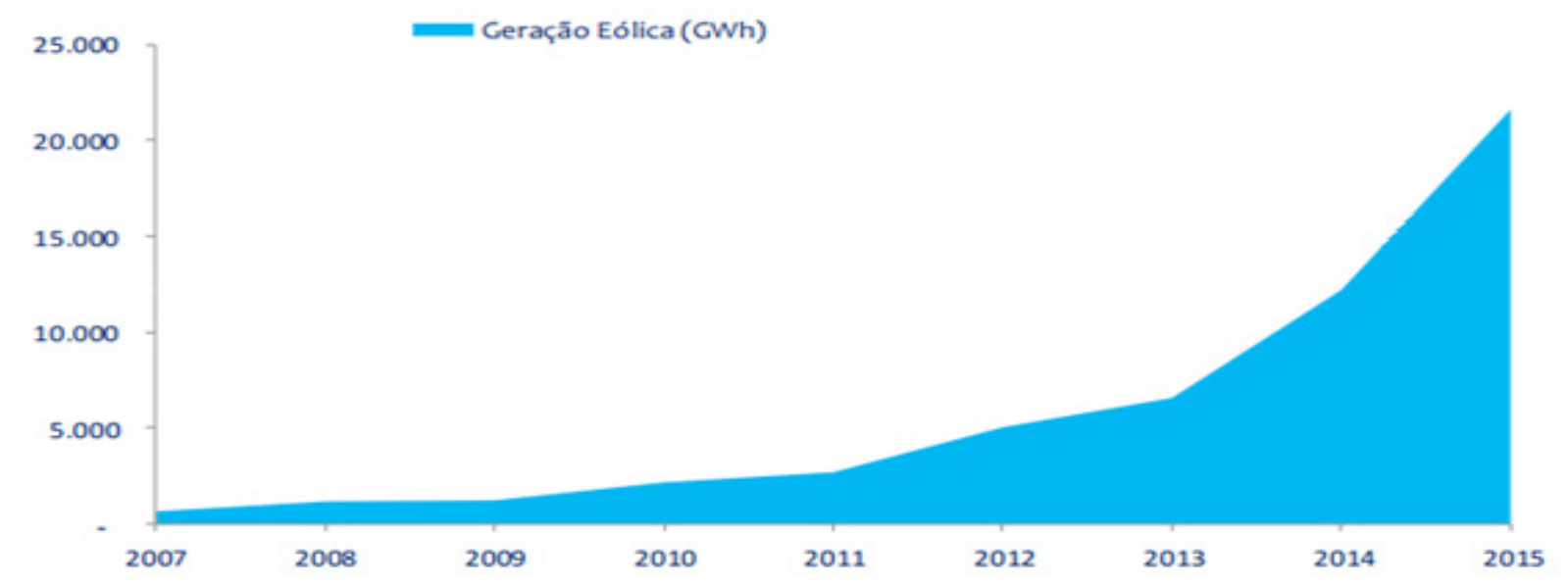

Fonte: Brasil (2016).

Seu desenvolvimento, também, se deve ao Protocolo de Kyoto de 1998, no qual foi acordado que os países dele participantes deveriam reduzir a emissão de gases-estufa na atmosfera, devido ao impacto da poluição no Planeta.

A expansão de fontes alternativas ou renováveis vem ocorrendo em diversos países, com intuito de reduzir impactos ambientais causados por combustíveis fósseis. A energia eólica tem se destacado por ter uma tecnologia disponível no mercado e com preços competitivos.

Esse trabalho tem como objetivo mostrar se há condições favoráveis ou não ao investimento em energia eólica no Brasil, no que tange aos fatores internos e externos que influenciam a expansão desse investimento. Nesse âmbito, foram utilizados por base fatores presentes na análise SWOT, verificando os pontos fortes, fracos, oportunidades e ameaças, e na análise PESTEL, pontuando a influência política, econômica, social, tecnológica, ambiental e legal. Para tanto, a escala Likert é utilizada para pontuar o quanto esses fatores podem influenciar os investimentos. Tal pesquisa se justifica pela necessidade de conhecer melhor o negócio do setor de energia eólica e verificar se há ou não barreiras à entrada, se é diversificada a matriz energética brasileira e se é ambientalmente mais adequada do que outras fontes de energia em utilização.

\section{BREVE HISTÓRICO SOBRE ENERGIA EÓLICA}

A origem da palavra "eólica" é do latim aeolicus, que se refere ao deus dos ventos da mitologia grega Éolo, conforme descreve Luna (2011). Segundo Righter (1996), o vento representa uma força primária da natureza que surge a partir de variações de temperatura e pressão do ar.

De acordo com o Ministério de Minas e Energia (MME) (BRASIL, 2016b), há milhares de anos, o vento vem sendo utilizado pela humanidade como força mecânica, impulso para embarcações e pressão para bombear água. Contudo não há prova convincente do conhecimento de moinhos de vento. Outras informações apontam para o surgimento de moinhos de vento na Pérsia por volta de 200 a.C.

Já para o Energy Information Administration (EIA, 2017), o uso do vento como fonte de energia foi a partir de 5.000 a.C., quando sua finalidade era impulsionar barcos ao longo do rio Nilo. Posteriormente, em 200 a.C., na China, Pérsia e Oriente Médio, o vento foi utilizado como energia para moinhos. 
O primeiro registro de utilização do vento para a produção de energia elétrica foi pelo professor James Blyth, na Escócia, em 1887, afirma o Ministério de Minas e Energia (BRASIL, 2016b). Blyth utilizou uma torre de $10 \mathrm{~m}$ de altura que carregava acumuladores alimentando a iluminação de uma casa de campo. Houve impasse na utilização da eletricidade por ter sido vista como "obra do diabo". Além disso, o invento não era economicamente viável, empecilho também à sua evolução.

Segundo Kaldellis e Zafirakis (2011), o primeiro grande moinho de vento que gerava 12 kW foi instalado em Cleveland, Ohio, nos EUA, em 1888. Este foi abandonado com a chegada de energia elétrica por meio de estações centrais. Após isso, as turbinas passaram a ser inspiradas em modelos europeus feitos após a Segunda Guerra Mundial, no período de 1935 a 1970. O mais importante desenvolvimento da energia eólica nos EUA aconteceu, com incentivo do governo americano, após a primeira crise do petróleo. No período de 1973 a 1990, a capacidade passou de 1 a 25kW para 50 a 250kW, contando com 16.000 turbinas eólicas registradas no estado da Califórnia.

Na década de 1990, houve um crescimento acelerado no setor de energia eólica por todo o mundo. A capacidade instalada total mundial de aerogeradores voltados à produção de energia elétrica atingiu 74.223 MW em 2006, um crescimento de cerca de 20\% em relação a 2005 (MARTINS; GUARNIERI; PEREIRA, 2008).

O Ministério de Minas e Energia (BRASIL, 2016b) relata que, com a tecnologia atual, já existem turbinas no exterior capazes de produzir entre 5 e $7 \mathrm{MW}$ em parques offshore - instalados no mar. No Brasil, as turbinas geram $3 \mathrm{MW}$ em torres de 100 metros ou mais, em parques onshore - instalados em terra.

No que tange à utilização da energia eólica, não há emissão de gases nem resíduos, não sendo necessário deslocamento de populações, animais ou plantas, e ainda, afirma Luna (2011), não inviabiliza a área utilizada. No entanto apresenta impactos socioambientais realizados pelas alterações e/ou atividades do ser humano, como impacto visual, emissão de ruídos, interferências eletromagnéticas, ocupação do espaço a ser instalado e riscos de colisão de aves - atrapalhando a fauna.

\section{METODOLOGIA}

A metodologia utilizada foi descritiva, explicativa e bibliográfica para levantamento dos dados utilizados para construir e apontar os pontos fortes e fracos da análise SWOT, bem como os itens da análise PESTEL. Descritiva para estabelecer relação entre as diversas variáveis técnicas, econômicas, sociais e ambientais do negócio em Energia Eólica. Este tipo de pesquisa visa identificar estruturas, formas, funções e contextos. Explicativa mostrando os fatos contributivos para o levantamento dos pontos fracos e fortes para a implantação do negócio em energia eólica no Brasil. Este tendo como principal meta verificar se há ou não barreiras para se estabelecer no mercado e manter o investimento. A coleta de dados foi realizada mediante levantamento bibliográfico em artigos, documentos e sites oficiais relacionados à energia tanto no Brasil, quanto em outros países.

Os itens da análise SWOT e PESTEL foram elaborados conforme leitura e análise realizada por autores de diversos sites, artigos da área de energia, como ANEEL, ELETROBRAS, MME e artigos acadêmicos da internet. Foram consultados livros, artigos, sites que tratam sobre investimento, administração e economia. 
Tem-se que a sigla SWOT como a abreviação das palavras em inglês: Strengths (Forças), Weaknesses (Fraquezas), Opportunities (Oportunidades) e Threats (Ameaças) e análise PESTEL (Político, Econômico, Social, Tecnológico, Ambiental e Legal), sendo realizado por meio da escala psicométrica Likert.

O método SWOT foi utilizado com o intuito de verificar os pontos positivos e negativos no investimento e impactos internos e externos da energia eólica no país. Tal método não se sabe exatamente quando foi desenvolvido. Segundo Nunes (2008), alguns estudiosos acreditam ter sido desenvolvido por Albert Humphrey (1970), já outros acreditam ter sido desenvolvido pelos professores de Harvard Business School: Kenneth Andrews e Roland Christensen. Segundo Tarapanoff (2001), esse tipo de análise possui quase três mil anos, considerando o que o autor Sun Tzu (2006) citou em seu livro A arte da guerra: "Concentre-se nos pontos fortes, reconheça as fraquezas, agarre as oportunidades e proteja-se contra as ameaças ".

Segundo Sparemberger e Zamberlan (2008), sua utilização possibilita a manutenção dos pontos fortes e a redução da intensidade de pontos fracos, aproveitando oportunidades e protegendo-se de ameaças. Assim, a análise SWOT possibilita a percepção de variáveis controláveis e incontroláveis para auxílio na tomada de decisões. Pode se definir a metodologia de análise SWOT como sendo o cruzamento de oportunidades e ameaças externas com uma organização de seus pontos fortes e fracos (CHIAVENATO; SAPIRO, 2003).

Figura 2 - Matriz SWOT incluindo análise PESTEL

\begin{tabular}{|c|c|c|}
\hline & Positivos & Negativos \\
\hline 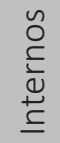 & Fortes & Fracos \\
\hline 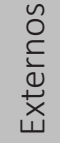 & Oportunidades & Ameaças \\
\hline
\end{tabular}

Fonte: Elaboração própria.

Assim, como pode ser observado na Figura 2, a análise será dividida em fatores internos e externos, sendo que estes foram subdivididos em pontos positivos e negativos. Os pontos negativos são aqueles que trazem dificuldades ou entraves ao investimento diretamente, enquanto que os pontos positivos fomentam o mesmo. Os fatores externos apresentam posição não multável, ou seja, não há como interferir diretamente, porém é possível reduzir seus impactos - quando os fatores são conhecidos. Desse modo, no âmbito externo, a influência se apresenta positiva quando a utilização do objeto de estudo não gera externalidades negativas irreversíveis e trazem oportunidades para o investimento em eólica, e negativa quando há afetação.

A análise PESTEL, neste estudo utilizada para assessorar a análise SWOT, é um aprimoramento da análise PEST, que significa Político, Econômico, Social e Tecnológico. Porém, com a evolução desta, foi incluída a parte legal e ambiental passando a ser conhecida como PESTEL. Para Johnson, Scholes e Whittington (2011), quando as organizações usam a análise PESTEL, fica mais fácil perceber e identificar os principais indicadores de mudanças e conflitos, pelos meios políticos, econômicos, sociais, tecnológicos, ambientais (ecológicos) e jurídicos. 
Dados esses que, ao gerar os indicadores, poderão ser utilizados na construção de cenários futuros proporcionando sucesso ou fracasso das estratégias de uma organização ou programa governamental.

Para tanto, foi utilizada a escala Likert pontuando os itens levantados para análise tanto de PESTEL quanto no âmbito de SWOT, relacionados à energia eólica (Tabela 1). A escala Likert é uma escala de mensuração criada por Rensis Likert em 1932, em que é considerada uma escala de 1 a 5 , tendo 1 como "desaprovo fortemente" e 5 "aprovo fortemente". Porém, neste trabalho, será considerado conforme Tabela 1.

Tabela 1 - Pontuação da escala Likert: Fonte de Energia Eólica no Brasil (FEEB)

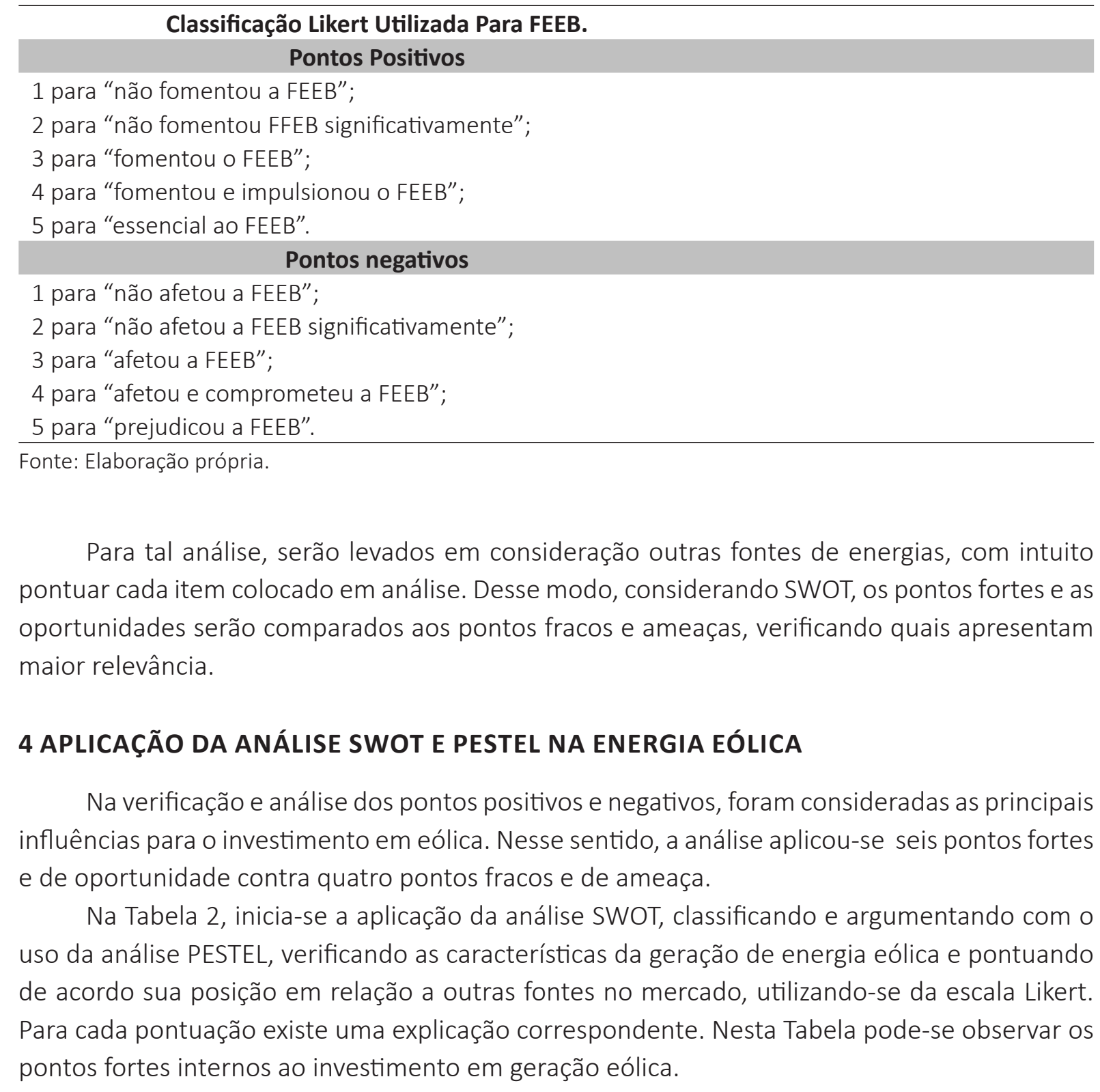


Tabela 2 - Fatores Internos a utilização da Fonte Eólica (Pontos Fortes)

\begin{tabular}{|c|c|c|c|}
\hline \multicolumn{2}{|c|}{ Fatores Internos Decisivos para o Investimento } & $\begin{array}{c}\text { Classificação } \\
\text { PESTEL }\end{array}$ & $\begin{array}{c}\text { Pontuação } \\
\text { Likert }\end{array}$ \\
\hline 1 & Afonte eólica é inesgotável e possui grande disponibilidade. & Econômico & 4 \\
\hline 2 & $\begin{array}{l}\text { Nas mesmas áreas de agricultura e/ou criação de gado } \\
\text { pode-se construir parques eólicos. }\end{array}$ & Econômico & 4 \\
\hline 3 & $\begin{array}{l}\text { Existe mercado imediato para consumo do produto final } \\
\text { com preço competitivo. }\end{array}$ & Econômico & 4 \\
\hline 4 & As turbinas não necessitam de manutenção tão frequente. & Econômico & 5 \\
\hline 5 & Tecnologia já é conhecida e desenvolvida. & Econômico e Tecnológico & 3 \\
\hline 6 & $\begin{array}{l}\text { Tempo de construção da usina eólica, período entre o } \\
\text { início e o fim das obras, é de aproximadamente 18 meses. }\end{array}$ & Econômico e Tecnológico & 5 \\
\cline { 2 - 4 } & \multicolumn{2}{|c|}{ TOTAL } & 25 \\
\hline
\end{tabular}

Fonte: Elaboração própria.

As justificativas da pontuação dada na escala Likert que estão na Tabela 2, são apresentadas a seguir:

1. A fonte eólica é inesgotável e possui grande disponibilidade-porém pode ser oscilante, fator econômico de grande importância na decisão de investir - não havendo possibilidades de limitar a utilização, onde a atuação do ser humano não impossibilita o uso futuro. Outras fontes também renováveis não apresentam essas mesmas condições, exceto a energia solar. Portanto a pontuação aplicada foi quatro, por não ser a única com essas qualidades e por depender da quantidade mínima de força do vento que é $4 \mathrm{~m} / \mathrm{s}$ (AGUSTINI, 2013).

2. Quando analisado o território a ser utilizado para a instalação de parques eólicos, no Brasil, é relativamente vasto. O parque pode ser instalado em áreas agrícolas sem interferir no funcionamento, ocupando pouco espaço onshore (é necessário estudo topográfico e orográfico) ou offshore, não ocupando espaço em terra. Diferente de outras fontes que utilizam a área apenas para produção de energia, como hidroelétricas e usinas nucleares (AGUSTINI, 2013). Esse fator foi pontuado em quatro, pois o caso offshore ainda não está sendo utilizado no Brasil. Ainda que seja vantagem onshore, ocupa espaço em terra.

3. A energia mecânica gerada pelo movimento dos ventos que batem nas hélices da turbina eólica, se transforma em energia elétrica. Este produto não tem problema de mercado, caso a energia gerada tenha linhas de transmissão para o devido transporte. Porém precisa competir por preço e tarifa com outras fontes de energia elétrica, que são mais baratas e acessíveis. O preço por megawatt-hora (MWh) no Brasil era de cerca de $\mathrm{R} \$$ 190 em 2008, enquanto em usinas hidroelétricas era em torno de R\$100. Em 2014, houve uma expansão e esse preço se reduziu, sendo vendido por R\$150 (TOLMASQUIN, 2016). Contudo, ainda não tem preço de mercado mais baixo que a hidroelétrica, sendo pontuado em quatro.

4. Considerando que, após o parque eólico montado, não há necessidade de constante manutenção, a tecnologia é eficiente, sendo necessária manutenção de 6 em 6 meses (SOARES, 2010). O fator econômico relacionado a manutenção foi pontuado em cinco, pois outras fontes como energia hidroelétrica precisam de grande equipe trabalhando constantemente para o funcionamento. 
5. A tecnologia da fonte eólica já foi desenvolvida e está disponível no mercado. De acordo com Camillo (2013), existe o modelo "tradicional" e o modelo "chinês" de produção dos componentes necessários à criação do parque eólico, porém não se pode controlar os preços e condições. Apesar de o Brasil já realizar a produção de alguns componentes das turbinas, ainda é refém da tecnologia, portanto esse fator foi pontuado em três.

6. Em relação ao tempo de construção, a usina eólica necessita de cerca de 18 meses para estar em funcionamento. Grande parte das fontes levam mais de 24 meses para estarem em funcionamento, como por exemplo energia hidroelétrica. Além disso, com 6 meses de funcionamento já se tem o retorno da energia utilizada para a instalação do parque eólico (CORREA, 2010). Fatores que permitem pontuar em cinco a fonte eólica.

Em continuidade à metodologia, foram analisados os pontos fracos considerando a análise SWOT na Tabela 3.

Tabela 3 - Fatores Internos a utilização da Fonte Eólica (Pontos Fracos)

\begin{tabular}{|c|c|c|c|}
\hline & Fatores Internos Decisivos para o Investimento & $\begin{array}{l}\text { Classificação } \\
\text { PESTEL }\end{array}$ & \begin{tabular}{|c|c|}
$\begin{array}{c}\text { Pontuação } \\
\text { Likert }\end{array}$ \\
\end{tabular} \\
\hline \multicolumn{4}{|c|}{ Pontos Fracos (Weaknesses) } \\
\hline 7 & $\begin{array}{l}\text { Pode não ser gerada em momentos necessários, por } \\
\text { depender da força dos ventos. }\end{array}$ & Econômico & 2 \\
\hline 8 & $\begin{array}{l}\text { Sua tecnologia foi desenvolvida na Europa e EUA, torna } \\
\text { dependente dos preços e condições. }\end{array}$ & $\begin{array}{l}\text { Econômico, Tecnológico, } \\
\text { Político e Legal }\end{array}$ & 4 \\
\hline 9 & Possibilidade da tecnologia se tornar obsoleta. & Econômico e Tecnológico. & 3 \\
\hline \multirow[t]{2}{*}{10} & Fator de capacidade com baixa eficiência & Tecnológico & 4 \\
\hline & & TOTAL & 13 \\
\hline
\end{tabular}

Fonte: Elaboração própria

Em continuidade à análise, têm-se as justificativas a seguir dos pontos fracos:

7. No que tange aos pontos fracos, a energia eólica depende da força dos ventos, portanto existe períodos em que a quantidade é baixa, não sendo suficiente para a geração de energia. Em Camillo (2013), tem-se que a velocidade mínima do vento necessária para que as turbinas eólicas entrem em operação é de $4 \mathrm{~m} / \mathrm{s}$. É um fator relevante, pois não há a certeza de que a energia estará disponível quando necessário. Outras fontes, também, têm restrições, como a energia solar que necessita de que os raios solares cheguem à superfície terrestre em quantidade suficiente para a geração e a energia hidráulica que possui variação sazonal, não sendo possível gerar energia em determinados períodos do ano (AGUSTINI, 2013). Fator pontuado negativamente em dois, pois não é um problema exclusivo da fonte eólica.

8. Levando em consideração que a tecnologia foi desenvolvida na Europa e EUA, os demais países precisam pagar para utilizar essa tecnologia. Devido a isso, o Brasil é dependente tecnologicamente na aquisição de partes da turbina e peças, até mesmo para realizar a produção local (CAMILLO, 2013). Esse fator é muito relevante negativamente, sendo pontuado em quatro. Fontes desenvolvidas nacionalmente não são dependentes. Esse fator é político, econômico, tecnológico e legal de dependência internacional.

9. Como toda tecnologia, existe a possibilidade da fonte eólica se tornar obsoleta. Isso acarretaria na dificuldade de se conseguir partes e/ou peças para sua manutenção. 
Além disso, poderia haver outros entraves, por não ser uma tecnologia nacional (BRASIL, 2016b). Esse fator é negativamente relevante, sendo pontuado em três.

10. O fator de capacidade de uma usina eólica está em torno de 32\%, comparativamente inferior à uma usina hidroelétrica que está em torno de 65\% (LEITE; FALCÃO; BORGES, 2006). Com isso, tem-se uma perda fortemente superior à fonte hidroelétrica no aproveitamento da energia gerada, pontuado em quatro.

A Tabela 4 apresenta os fatores externos a produção de energia eólica, pontos que oportunizam o seu uso, classificados e pontuados.

Tabela 4 - Fatores Externos a utilização da Fonte Eólica (Pontos de Oportunidade)

\begin{tabular}{|c|c|c|c|}
\hline \multicolumn{2}{|r|}{ Fatores Externos } & $\begin{array}{l}\text { Classificação } \\
\text { PESTEL }\end{array}$ & $\begin{array}{l}\text { Pontuação } \\
\text { Likert }\end{array}$ \\
\hline \multicolumn{4}{|c|}{ Pontos de Oportunidade (Opportunities) } \\
\hline 11 & Não emissão de gases poluentes. & Ambiental & 4 \\
\hline 12 & Não geração de resíduos. & Ambiental e Econômico & 5 \\
\hline 13 & É uma energia renovável. & Ambiental & 5 \\
\hline 14 & Novas oportunidades de trabalho. & Político e Econômico & 3 \\
\hline 15 & $\begin{array}{l}\text { Áreas podem ser reutilizadas em caso de desativação do } \\
\text { parque. }\end{array}$ & Econômico e Ambiental & 4 \\
\hline \multirow[t]{2}{*}{16} & Diversificação da Matriz Energética. & Político e Econômico & 4 \\
\hline & & TOTAL & 25 \\
\hline
\end{tabular}

Fonte: Elaboração própria

As justificativas, assim como a pontuação e a aplicação da escala Likert, são apresentadas a seguir:

11. A não produção de gases nocivos é muito relevante positivamente na fonte eólica entretanto existem outras fontes que também não produzem, como a energia solar (AGUSTINI, 2013). Portanto foi pontuado em quatro, sendo um benefício não exclusivo da fonte eólica.

12. Não há geração de resíduos de nenhum tipo na geração eólica. Nesse sentido, foi pontuado em 5 (cinco), pois é um dos principais benefícios da fonte eólica, além de ser um ponto também ecologicamente importante.

13. A fonte eólica é totalmente renovável. Outras fontes não renováveis como o petróleo, não têm capacidade de reposição em curto prazo (milhares de centenas de anos para recompor), após extraído todo o petróleo de uma jazida. Com isso, esse fator foi pontuado positivamente em cinco, sendo de grande influência ao desenvolvimento da fonte.

14. O parque eólico gera empregos para ser construído, principalmente indiretos, com a expansão e desenvolvimento em torno da usina eólica. Apesar de ser um fator positivamente relevante, foi pontuado em três, pois os empregos diretos que permanecerão após a instalação do parque, não são muitos, devido à baixa necessidade de manutenção e suporte. Em contrapartida, fontes como biomassa geram grande quantidade de empregos diretos.

15. As áreas onde são instalados os parques eólicos podem ser onshore com possibilidade de ser reutilizadas em caso de desativação do parque, podendo também ser offshore (em mar) que nem sequer ocupa espaço em terra. Em contrapartida, fontes como energia 
nuclear não permitem que haja reutilização. Nesse sentido, esse fator foi pontuado em quatro, pois a utilização offshore ainda não é utilizada no Brasil.

16. A diversificação de fonte de energia é um fator relevante, porém, existem diversas fontes renováveis substitutas que, também, podem ser utilizadas, como biomassa, solar e hidráulica, sendo pontuado em quatro.

A Tabela 5 reflete os valores dos pontos de ameaças que poderão influenciar nos investimentos em energia eólica no Brasil.

Tabela 5 - Fatores Externos a utilização da Fonte Eólica (Pontos de Ameaça)

\begin{tabular}{|c|c|c|c|}
\hline & Fatores Externos & $\begin{array}{l}\text { Classificação } \\
\text { PESTEL }\end{array}$ & \begin{tabular}{|c|c|} 
Pontuação \\
Likert
\end{tabular} \\
\hline \multicolumn{4}{|c|}{ Pontos de Ameaça (Threats) } \\
\hline 17 & Geração de poluição sonora (ruídos) e visual. & Social & 3 \\
\hline 18 & $\begin{array}{l}\text { Não é autossuficiente, sendo necessária outra fonte em } \\
\text { simultâneo. }\end{array}$ & Econômico e Ambiental & 4 \\
\hline 19 & Pode afetar a fauna. & Ambiental & 3 \\
\hline \multirow[t]{2}{*}{20} & Gera interferências eletromagnéticas. & Social & 3 \\
\hline & & TOTAL & 13 \\
\hline
\end{tabular}

Fonte: Elaboração própria

As justificativas, assim como a pontuação e a aplicação da escala Likert, são apresentadas a seguir:

17. Entre as ameaças ou dificuldades de se utilizar a Eólica, tem-se o ruído. Conforme Agustini (2013), é necessário assumir uma distância de 500 metros entre residências e geradores eólicos. Os aerogeradores podem emitir até $50 \mathrm{~dB}$, contudo, assumindo a distância de 500 metros distância, o máximo será de $35 \mathrm{~dB}$. Ruídos acima de $65 \mathrm{~dB}$ podem causar efeitos fisiológicos ao homem como danos no sistema auditivo. Quanto à poluição visual, há uma alteração na paisagem local, podendo ser incômodo ou não para diferentes indivíduos. Os impactos sociais e ambientais desses fatores não podem ser desconsiderados, por isso, foi pontuado em três.

18. Analisando sua disponibilidade de geração, é possível perceber que esta depende da força dos ventos. Esse fator externo é incontrolável (também abordado no item 7), sendo uma fonte complementar, ou seja, não se pode ter somente esta, é necessária outra fonte em simultâneo para complementar paralelamente essa energia. Porém isto acontece com diversas outras fontes, como a solar, que depende da disponibilidade de sol. Esse fator foi pontuado negativamente em quatro, pois não permite que essa seja a única fonte utilizada.

19. Tem-se outra externalidade negativa que é a afetação da fauna. Um parque eólico tende a gerar colisões de aves nas hélices e pode vir a afetar a migração de aves. Tal fator é de grande relevância, devendo ser analisado com cautela antes da construção do parque eólico, principalmente em se tratando de áreas com grande densidade de aves (AGUSTINI, 2013). Porém não é impeditivo, sendo pontuado em três.

20. Percebe-se que pode haver interferências eletromagnéticas nas ondas de rádio, telefone e/ou internet, porém avanços na tecnologia têm reduzido bastante esse quesito (CORREA, 2010). Tal fator foi pontuado negativamente em três, pois não chega a influenciar de modo a ser impeditivo. 
A Tabela 6 demonstra o resultado da análise da energia eólica, com a aplicação da metodologia definida neste trabalho.

Tabela 6 - Resultado da Análise da Fonte Eólica

\begin{tabular}{|c|c|c|}
\hline & Positivos & Negativos \\
\hline 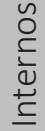 & $\begin{array}{c}\text { Fortes } \\
25\end{array}$ & $\begin{array}{c}\text { Fracos } \\
13\end{array}$ \\
\hline 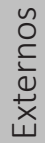 & $\begin{array}{l}\text { Oportunidades } \\
25\end{array}$ & $\begin{array}{c}\text { Ameaças } \\
13\end{array}$ \\
\hline
\end{tabular}

Fonte: Elaboração própria

Os investimentos em empreendimentos de energia eólica no Brasil são favoráveis, nota-se que, nos fatores internos, são predominantes os pontos fortes que obtiveram em 25 (Tabela 2), enquanto os pontos fracos resultaram em 13 (Tabela 3), não sendo impeditivos à implantação dos empreendimentos, de acordo com esta análise.

As oportunidades são também significativas nos fatores externos, demonstrando que há um vasto campo de desenvolvimento para esta modalidade de energia, pontuado em 25 (Tabela 4); sobrepõe fortemente em relação às ameaças, pontuadas em 13 (Tabela 5), que nesta análise não são significativas e impeditivas à implementação dos empreendimentos.

Com isso, tem-se que os pontos positivos foram 50, e os negativos, 26. Contudo a análise foi realizada com 12 pontos positivos contra oito negativos. Nesse sentido, os pontos negativos foram amplificados em um terço para realizar equiparação dos fatores. Assim, os pontos positivos são 50 contra 34,6 negativos, apresentando as vantagens superiores às desvantagens.

\section{DISCUSSÃO DOS RESULTADOS DE SWOT E PESTEL NO INVESTIMENTO EM ENERGIA EÓLICA}

Conforme a análise realizada utilizando SWOT e PESTEL com a classificação de acordo com a escala Likert, a fonte é viável e economicamente competitiva no mercado, apresentando um cenário positivo a sua introdução e/ou expansão.

Dentre os fatores internos determinantes do investimento, tem-se a força dos ventos. A energia eólica não pode ser a única fonte utilizada para obtenção de eletricidade, pois há momentos em que a força dos ventos não se faz suficiente. Esse fator que se apresenta como negativo, não desencoraja os investimentos no setor, pois é uma fonte inesgotável e possui grande disponibilidade.

Outro fator negativo é a tecnologia não ter sido desenvolvida no Brasil, contudo a fonte está em grande desenvolvimento no mundo - inclusive com incentivos da Europa e EUA, que buscam expandir-Ihe o uso. Com o aumento da demanda, existe a possibilidade de redução de custos para todos os envolvidos no uso da fonte eólica.

Quanto à possibilidade de a tecnologia se tornar obsoleta, sempre haverá esse risco, porém os lucros proporcionados por uma usina eólica já teriam superado os custos, visto que a durabilidade de uma turbina é de cerca de 20 anos (TOLMASQUIN, 2016). 
Já o fator capacidade é muito importante, pois o aproveitamento da eletricidade é em torno de $32 \%$, sendo um fator negativo. Porém não gera redução nos investimentos por ser economicamente viável, ainda que haja perdas.

Com isso, os fatores negativos se mostram tímidos frente aos fatores positivos que incentivam os investimentos na fonte eólica. Na esfera econômica, é considerado viável o investimento, devido a vida útil da usina, baixa manutenção, existência de mercado imediato e o fato de a fonte utilizada ser inesgotável, possuindo grande disponibilidade.

Dentre os fatores externos, os pontos de ameaça são a poluição visual e sonora, as interferências eletromagnéticas e os impactos na fauna. Esses fatores, quando levadas em consideração as dimensões do Brasil, podem não se apresentar como impeditivos, pois é possível realizar a implementação de usinas afastadas de residências, e o estudo apropriado do fluxo de aves na região pode reduzir os riscos de afetação da fauna.

Já nos pontos de oportunidade, a sociedade se beneficia amplamente da geração de eletricidade através da fonte eólica, por esta não emitir gases poluentes, não gerar resíduos, gerar novas oportunidades de trabalho, não danificar o solo, podendo ser reutilizado, bem como diversificada a Matriz Energética.

É possível perceber também que a geração de eletricidade através da fonte eólica, além de trazer benefícios à sociedade, tem qualidades que impulsionam o investimento e ampliação do setor tanto para o Brasil quanto para outros países. A importância da fonte se corrobora com o cenário em que ela se encontra mundialmente e a perspectiva futura de que ela represente no mínimo 27\% do consumo mundial de eletricidade em 2030 (GSR, 2016).

\section{CONCLUSÃO}

A análise SWOT e PESTEL permitiu demostrar que o investimento em geração eólica é vantajoso e colabora para diversificação da matriz energética nacional, sendo propício realizar o investimento e expansão no Brasil. As vantagens geram benefícios superiores às desvantagens, a sociedade se beneficia da não emissão gases poluentes, não geração resíduos, geração de novas oportunidades de trabalho, não danificação do solo e diversificação da Matriz Energética. O investidor também tem benefícios superiores aos negativos, como a vida útil da usina, baixa manutenção, existência de mercado imediato e o fato de ser inesgotável, possuindo grande disponibilidade.

\section{REFERÊNCIAS}

AGUSTINI, C. B. Perspectiva do mercado brasileiro no setor elétrico eólico. 2013. Trabalho de Diplomação (Bacharelado em Engenharia Química) - Universidade Federal do Rio Grande do Sul (UFRGS), Porto Alegre, 2013. Disponível em: <http://hdl.handle.net/10183/108448>. Acesso em: 23 mar. 2017.

BRASIL. Balanço Energético Nacional (BEM). 2016a. Disponível em: <https://ben.epe.gov.br/downloads/ Relatorio_Final_BEN_2016.pdf>. Acesso em: 22 fev. 2017.

BRASIL. Ministério de Minas e Energia (MME). A energia eólica no Brasil e no mundo, 2016b. Disponível em: <http://www.mme.gov.br/documents/10584/3894319/Energia+E\%C3\%B3lica+-+ano+ref++2015+(3). pdf/f5ca897d-bc63-400c-9389-582cd4f00ea2>. Acesso em: 9 fev. 2017.

CAMILLO, E. V. As políticas de inovação da indústria de energía eólica: uma análise do caso brasileiro com base no estudo de experiências internacionais. 2013. Tese (Doutorado em Política Científica e Tecnológica) - Universidade Estadual de Campinas (UNICAMP), Campinas, SP, 2013. Disponível em: <http://pct.capes. gov.br/teses/2013/33003017047P2/TES.PDF>. Acesso em: 28 fev. 2017. 
CHIAVENATO, I.; SAPIRO, A. Planejamento estratégico: fundamentos e aplicações. 1. ed., 13. tiragem. Rio de Janeiro: Elsevier, 2003.

CORREA, P. M. Energia eólica: análise teórica e sua aplicação no mundo. 2010. Monografia (Bacharelado em Ciências Econômicas) - Universidade Federal do Rio Grande do Sul (UFRGS), Porto Alegre, 2010. Disponível em: <http://hdl.handle.net/10183/26101>. Acesso em: 15 fev. 2017.

ENERGY INFORMATION ADMINISTRATION (EIA). History of wind power. Disponível em: <http://www.eia. gov/energyexplained/index.cfm?page=wind_history>. Acesso em: 9 fev. 2017.

GLOBAL STATUS REPORT (GSR). Renewable Energy Policy Network for The 21st Century. 2016. Disponível em: <http://www.ren21.net/wp-content/uploads/2016/10/REN21_GSR2016_FullReport_en_11.pdf>. Acesso em: 4 fev. 2017.

JOHNSON, G.; SCHOLES, K.; WHITTINGTON, R. Fundamentos de estratégia. Porto Alegre: Bookman, 2011. KALDELLIS, J. K.; ZAFIRAKIS, D. The wind energy (r)evolution: a short review of a long history. Renewable Energy, v. 26, n. 7, p. 1887-901. jul. 2011. Disponível em: <http://www.sciencedirect.com/science/article/ pii/S0960148111000085>. Acesso em: 13 fev. 2017.

LEITE, A. P.; FALCÃO, D. M.; BORGES, C. L.T. Modelagem de usinas eólicas para estudos de confiabilidade. Sba: Controle \& Automação Sociedade Brasileira de Automatica, Campinas, SP, v. 17, n. 2, p. 177-88, abr./jun. 2006. Disponível em: <http://dx.doi.org/10.1590/S0103-17592006000200006>. Acesso em: 25 mar. 2017.

LUNA, N. A. Avaliação de empresas utilizando a teoría das opções reais: o caso de uma geradora de energia eólica. 2011. Dissertação (Mestrado em Economia) - Universidade Federal do Rio Grande do Sul (UFRGS), Porto Alegre, 2011. Disponível em: <http://hdl.handle.net/10183/30855>. Acesso em: 25 fev. 2017.

MARTINS, F. R.; GUARNIERI, R. A.; PEREIRA, E. B. O aproveitamento da energia eólica. Revista Brasileira de Ensino de Física, São Paulo, v. 30, n. 1, 2008. Disponível em: <http://www.scielo.br/scielo.php?script=sci_ar ttext\&pid=S1806-11172008000100005>. Acesso em: 20 mar. 2017.

NUNES, A. F. Glossário de termos econômicos e financeiros: mercado de capitais, financeiro e de crédito. 3. ed., rev. e aum. Rio de Janeiro, 2008.

RIGHTER, R. W. Wind energy in America - a history. Oklahoma, EUA: University of Oklahoma Press, 1996.

SOARES, L. T. Planejamento e implantação de um parque eólico. 2010. Trabalho Final de Curso (Graduação em Engenharia Elétrica) - Universidade Federal do Ceará (UFC), Fortaleza, 2010. Disponível em: <http:// www.dee.ufc.br/anexos/TCCS/2010.1/LUCIANE\%20TEIXEIRA\%20SOARES. pdf>. Acesso em: 25 mar. 2017.

SPAREMBERGER, A.; ZAMBERLAN, L. Marketing estratégico. Ijuí, RS: Ed. Unijuí, 2008. Disponível em: <http://bibliodigital.unijui.edu.br:8080/xmlui/bitstream/handle/123456789/182/Marketing\%20 estrat\%C3\%A9gico.pdf?sequence=1>. Acesso em: 21 mar. 2017.

TARAPANOFF, K. (Org.). Inteligência organizacional e competitiva. Brasília: Editora UNB, 2001.

TOLMASQUIN, M. T. Energia renovável: hidráulica, biomassa, eólica, solar, oceânica. Rio de Janeiro: EPE, 2016.

TZU, S. A arte da guerra. Tradução de Sueli Barros Cassal. Porto Alegre: L\&PM, 2006. Disponível em: <http://unes.br/Biblioteca/Arquivos/A_Arte_da_Guerra_L\&PM.pdf>. Acesso em: 22 mar. 2017.

\section{Sobre os autores}

Vitor Silva Damasceno: Economista pela Universidade Federal do Tocantins. E-mail: vitorsd@uft.edu.br

Yolanda Vieira de Abreu: Pós-Doutora pelo Instituto de Economia da UNICAMP. Doutora em Sistemas de Planejamento de Sistemas Energéticos FEM/UNICAMP. Mestre em Interunidades (FEA/EP/IEE e IF) em Energia IEE/USP. Bacharel em Economia pela PUC/SP. Professora Associada IV, Curso de Economia e no Mestrado em Agroenergia da Universidade Federal do Tocantins. Atua nas seguintes áreas: economia de energia, economia agrícola, economia agrária e economia brasileira. E-mail: yolanda@uft.edu.br 